\title{
GFRP Reinforced Concrete Beams
}

\section{IIIII uOttawa Spencer Manoryk, Supervisor: Dr. Martin Noël and M.ASc Candidate Danielle Pacheco UROP \\ Department of Civil Engineering, University of Ottawa}
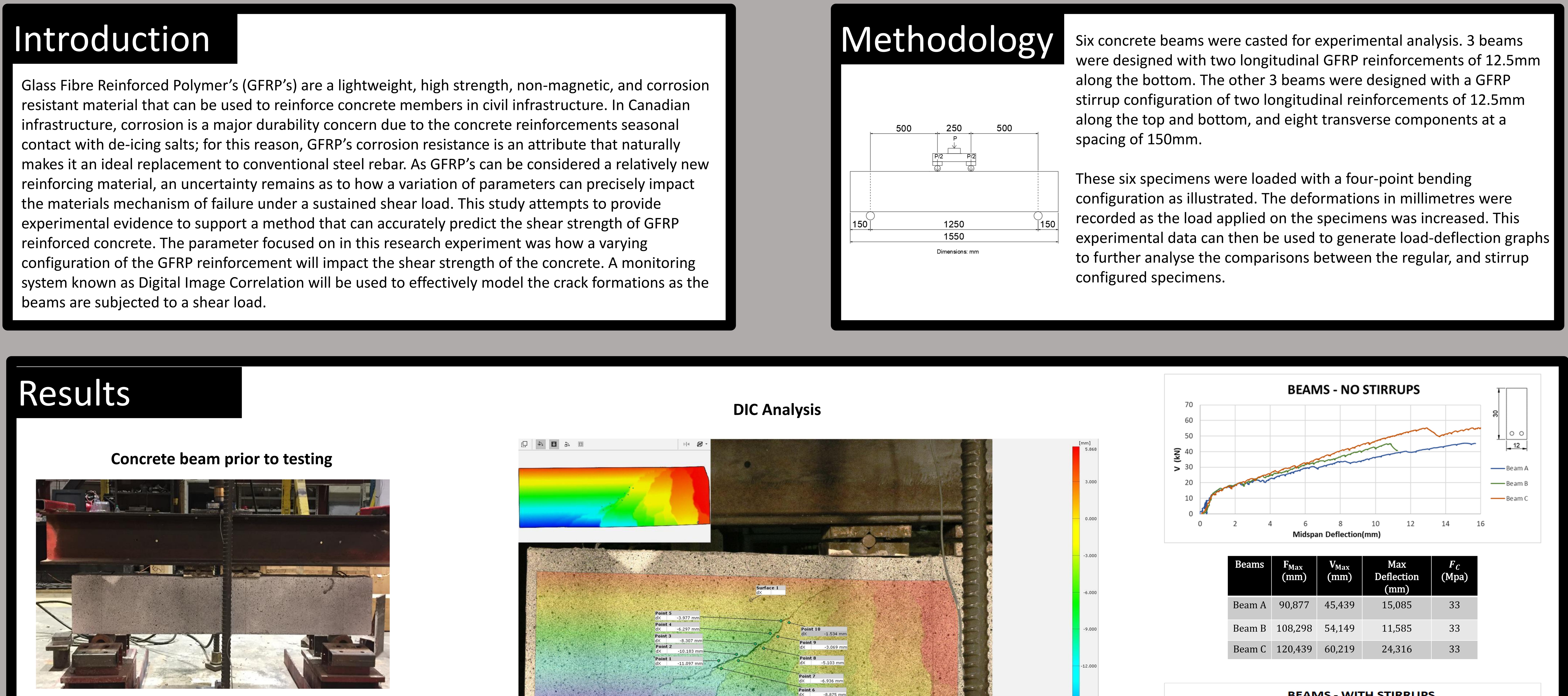

Concrete beam after testing
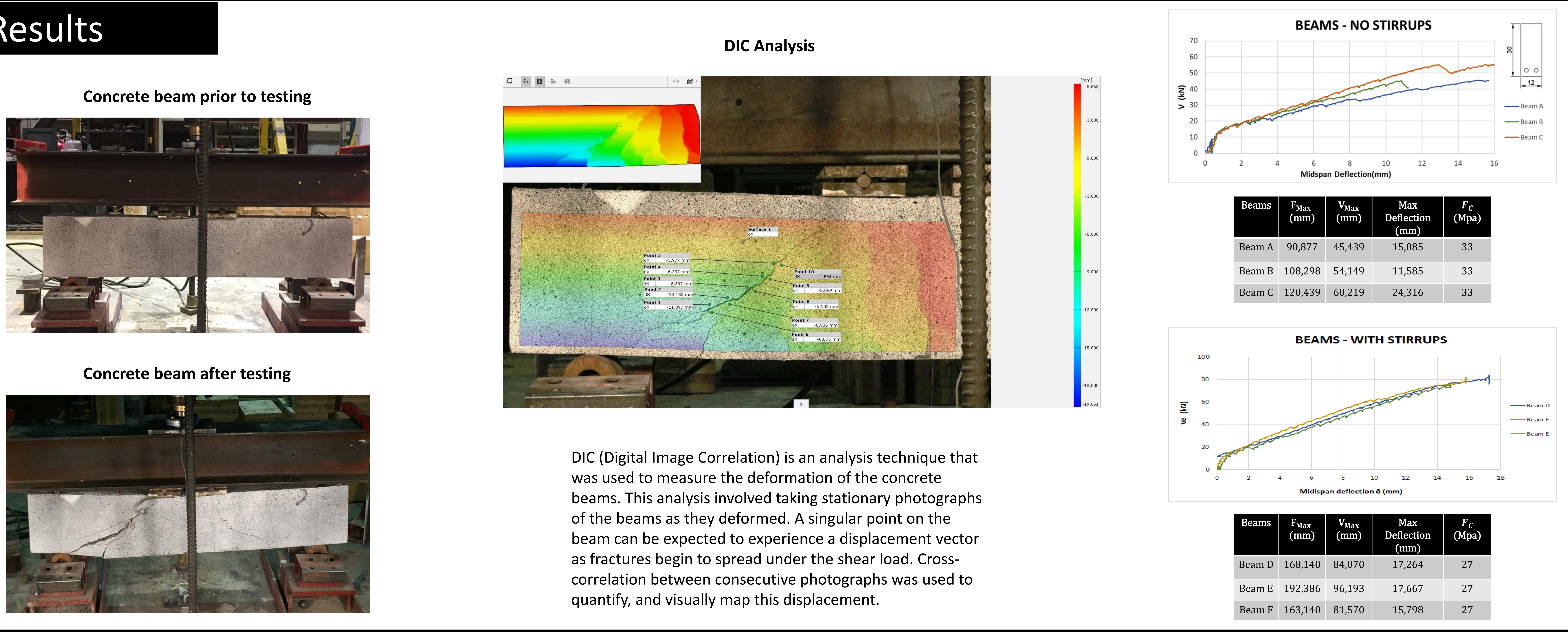

\section{Conclusions}

In conclusion it can be said that the results of this research have been successful. Complications could

have arose throughout the casting and set-up phase of the beams; however, as proper safety precautions were taken throughout the duration of this research, it allowed for the generation and testing of successful specimens. Upon analyzing the data, it can be noted that on average the beams with stirrups were able to withstand a larger maximum shear force and total mid-span deflection than the beams without the stirrups. Through DIC analysis of the beams with stirrups, it can be seen that cracks formed from the corners and spread at a steeper angle than those without the stirrups. Furthermore, through post-experimental analysis it was observed that failure was governed by the rupture of the stirrup. The results from this experimental will be used in correlation with push-off and dowel action tests, to generate a rational shear model to track the crack kinematics of GFRP reinforced concrete beams.

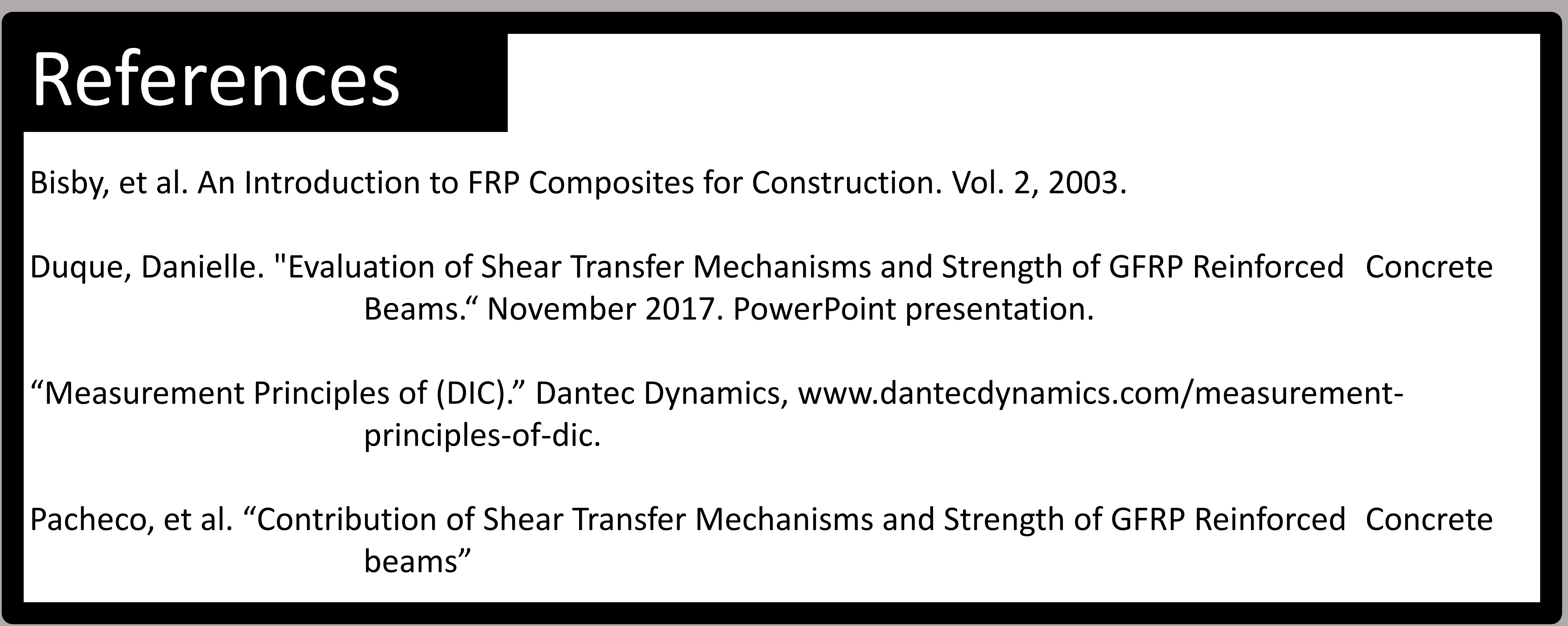

